\title{
Perceived Health Status of and Moderating Factors in Elderly People Caring for Their Grandchildren
}

\author{
Kyoung Min Kim ${ }^{1,2}$, Jung Jae Lee ${ }^{1,2}$, and Un Sun Chung ${ }^{3 凶}$ \\ ${ }^{1}$ Department of Psychiatry, Dankook University Hospital, Cheonan, Republic of Korea \\ ${ }^{2}$ Department of Psychiatry, Dankook University College of Medicine, Cheonan, Republic of Korea \\ ${ }^{3}$ Department of Psychiatry, Kyungpook National University College of Medicine, Daegu, Republic of Korea
}

\begin{abstract}
Objective Situations in which elderly people are the primary caregivers for their grandchildren are becoming more common. This study aimed to investigate moderating factors of and the association between grandchild care and the grandparents' perceived health. Financial support in return for grandchild care was also investigated as a moderating factor.

Methods Participants included 357 elderly people over the age of 60 years. The assessment to evaluate the perceived health status and social support was performed via a questionnaire. It included questions regarding the care of grandchildren and demographic variables, as well as the Medical Outcome Survey (MOS) 36-item short-form health survey (SF-36), and the MOS Social Support Survey (MOSSSS).

Results The subscale scores of SF-36 and MOS-SSS did not differ significantly for grandchild-care status. However, the subscale scores of SF-36 were significantly higher in groups that received regular financial support from adult children in return for grandchild care than in groups that did not.

Conclusion Our data suggest that regular financial support in return for grandchild care may be a moderating factor in the association between grandchild care and the perceived health status of elderly people. These findings have important social implications and warrant future study to reveal the psychological mechanism of these associations and enhance the health of elderly individuals.
\end{abstract}

Psychiatry Investig 2020;17(4):275-282

Key Words Elderly people, Financial support, Grandchild care, Health status, Social support.

\section{INTRODUCTION}

As the life expectancy of humans and the employment of mothers both increase worldwide, more grandparents find themselves caring for their grandchildren. Despite significant variations in the prevalence of grandchild care in different countries with varying maternal employment regimes, a study performed in 10 European countries reported that $58 \%$ of grandmothers and $49 \%$ of grandfathers cared for their grandchildren under the age of 16 in the past year. ${ }^{1}$ In the United States, the prevalence of grandparent-and-grandchild co-residence in-

Received: May 12, 2019 Revised: August 4, 2019

Accepted: October 20, 2019

$\triangle$ Correspondence: Un Sun Chung, MD, PhD

Department of Psychiatry, Kyungpook National University Children's Hospital, 807 Hoguk-ro, Buk-gu, Daegu 41404, Republic of Korea

Tel: +82-53-200-6414, Fax: +82-53-426-5361

E-mail: unsunchung@gmail.com

(a) This is an Open Access article distributed under the terms of the Creative Commons Attribution Non-Commercial License (https://creativecommons.org/licenses/bync/4.0) which permits unrestricted non-commercial use, distribution, and reproduction in any medium, provided the original work is properly cited. creased from $3.2 \%$ in 1970 to $5.5 \%$ in $2003 .^{2}$ In addition, $24 \%$ of preschoolers in the United States were regularly cared for by a grandparent. ${ }^{3} \mathrm{~A}$ Taiwanese study also reported that the percentage of elders providing care for grandchildren dramatically increased from $9 \%$ in 1993 to $21 \%$ in $2007 .{ }^{4}$ In Korea, the percentage of children cared for by a grandparent was reported to be as high as $37.2 \%$ in $2016 .^{5}$ The rate of grandchild care is reported to be higher in cases of employed mothers (53\%) than in cases of unemployed mothers (43\%) in USA. ${ }^{3}$ This is also the case in Korea; the rate of grandchild care is $53.7 \%$ in cases of employed mothers and only $25.8 \%$ in cases of unemployed mothers. ${ }^{5}$ Further, the younger the child was, the more support was required from the grandparents; $70.7 \%$ of children younger than 1 year required grandparent care. ${ }^{5}$

Raising a child is physically and emotionally challenging, but it also provides emotional rewards. As such, research regarding the relationship between grandchild care and the health of the grandparent is inconclusive. ${ }^{6}$ Multiple studies reported positive associations between grandchild care and the health and 
wellbeing of grandparents. ${ }^{6-10}$ For instance, Di Gessa et al. ${ }^{7}$ reported that both intensive and non-intensive experiences with caring for grandchildren provided some health benefits to the grandparents. Ku et al. ${ }^{8}$ also reported that long-term multigenerational caregivers were more likely to report better self-rated health, higher life satisfaction, and fewer depressive symptoms when compared with non-caregivers. Older veterans with a diagnosis of posttraumatic stress disorder (PTSD) reported reduced symptoms after caring for their grandchildren. ${ }^{10}$

On the contrary, other studies showed a negative association between grandchild care and the health of the grandparents. ${ }^{11-14}$ Grandparents caring for grandchildren were more likely to experience depressive and isolated feelings. ${ }^{12}$ Custodial grandparents in particular were vulnerable to unfavorable health outcomes such as limited activities of daily living (ADLs) or depressive and isolated feelings. ${ }^{11,13}$

However, multiple studies reported that the relationship between grandchild care and the health of grandparents is not a positive/negative linear relationship. Rather, there are various moderating factors involved, such as the intensity of caring, the amount of social support, the relationships among family, and the characteristics of the grandparents themselves. ${ }^{15-18}$

Coall and Hertwig ${ }^{16}$ reported that the relationship between a grandparent's wellbeing and the intensity of care has an inverted u-shape, and very-low and very-high intensity of care can have a negative effect on both a grandparent's wellbeing and the development of grandchildren. Chen and $\mathrm{Liu}^{17}$ also reported that high intensity care of younger grandchildren accelerated health declines, whereas lighter levels of care had a protective effect.

Social support is another main factor involved in the health of grandparents caring for their grandchildren. In a longitudinal study, Hayslip et al. ${ }^{19}$ reported that social support moderated the effects of parental stress on depression. Musil et al. ${ }^{20}$ also reported that social support moderated the effects of strain and family-life stresses on depressive symptoms in grandparents.

The characters of grandchildren, such as abnormal emotional or hyperactive symptoms, also contribute to higher levels of anxiety and depression in grandparents caring for grandchildren. ${ }^{21}$ In addition, stressors such as depression and anxiety of grandparents may arise from certain grandparent characteristics, such as being female, in poverty, or of ethnic minority. ${ }^{22}$

Financial support from grown-up children is a common phenomenon in Asian culture, as it contributes to the fulfillment of the virtue of filial piety. ${ }^{23,24}$ Financial support in return for grandchild care is common in Korea, but not as common in Western countries. ${ }^{25}$ Cong and Silverstein ${ }^{23}$ reported financial support from grown-up children reduced depression of grandparent. The psychological benefits were the most pronounced when financial support was accompanied by full- time grandchild care. However, studies examining the effect of financial support by grown-up children on grandchild care are limited. Our study investigated the association between and moderating factors of grandchild care and perceived grandparent health. Financial support in return for grandchild care was also investigated as a moderating factor.

\section{METHODS}

\section{Participants}

Study data were collected from the Suseong Mental Health Care Program for the Elderly, which was performed in Daegu, the fourth largest city in South Korea with a population of 2.5 million, during 2011. The participants included 357 elderly people over the age of 60 ; the number of male participants was 149 (41.7\%). The age of the participants ranged from 60 to 93 , with an average age of 72.12. All participants gave written informed consent after being provided with a complete explanation of the project. They were then questioned by the trained interviewer. The study protocol was approved by the Institutional Review Board for Human Subjects of a university hospital in Cheonan, South Korea (2018-12-004).

\section{Assessment}

The assessment was performed via a questionnaire on demographic variables and other relevant information about grandchild care. Questions inquired about the grandparent's experience with grandchild care, financial support from children, motivation and reason for grandchild care and intensity of grandchild care, the probability of continued grandchild care, the kind of support needed, and benefits from grandchild care.

The questionnaire also included the Medical Outcome Survey (MOS) 36-item short-form health survey (SF-36) and the MOS Social Support Survey (MOS-SSS). The SF-36 is a multiitem scale that assesses eight health concepts: 1) limitations in physical functioning; 2) limitations in social functioning; 3) limitations to usual roles due to physical problems; 4) limitations to usual roles due to emotional problems; 5) general mental health; 6) vitality; 7) bodily pain; and 8) general health perceptions. ${ }^{26}$ The MOS-SSS is a scale for the assessment of perceived social support that consists of 19 items and subscales for emotional/informational support, tangible support, positive social interaction, and affection support. ${ }^{27}$ The scores for subscales of the SF-36 and the MOS-SSS were converted to a range from 0 to 100 using the formula (raw sum - possible minimum score $) \div($ possible maximum score - possible minimum score) $\times 100$.

\section{Statistical analysis}

Demographic variables and items related to grandchild care 
were analyzed using frequency analysis, chi-squared tests, and analysis of variances (ANOVA). The participants were categorized into three groups: 1) those who were currently caring for their grandchildren (Current group), 2) those who had cared for their grandchildren previously but not currently (Past group), and 3) those who had never cared for their grandchildren (None group). The ANOVA was used to test for any statistically significant differences between these three groups on subscales of the SF-36 and the MOS-SSS.

The grandparents who had experienced grandchild care were further categorized into two groups: 1) those who received regular financial support in return for grandchild care (Pay group) and 2) those who did not receive regular financial support in return for grandchild care (the No pay group). The SF36 and the MOS-SSS scores between the Pay group and No pay group were compared using three models. Model 1 used multivariate analysis of variance (MANOVA) without considering any covariates. Model 2 used a multivariate analysis of covariance (MANCOVA) with age, sex, educational level, household income level, marital status, and employment status as covariates. Model 3 included the intensity of grandchild care in addition to model 2 .

To examine the association between financial support group (pay group) and the SF-36 subscales, a generalized linear model (GLM) was used, with the covariates of age, sex, educational level, household income level, marital status, employment status, and financial support (model 1). Model 2 included the intensity of grandchild care in addition to model 1 . To determine whether there was a correlation between the amount of financial support received and scores on the SF-36 and the MOS-SSS, Pearson's correlation coefficient was used. All data were analyzed using the Statistical Package for the Social Sciences (SPSS) statistical software, version 25.0 (IBM Corp., Armonk, NY, USA).

\section{RESULTS}

\section{Demographic characteristics}

The demographic characteristics of participants are shown in Table 1 . The age, education, and income levels were not sig-

Table 1. Demographic characteristics of the participants

\begin{tabular}{|c|c|c|c|c|c|}
\hline Experience of grandchild care & None group & Current group & Past group & Statistics & $\mathrm{p}$ \\
\hline $\mathrm{N}(\%)$ & $228(63.9)$ & $55(15.4)$ & $74(20.7)$ & & \\
\hline Mean (SD) years old & $72.42(7.93)$ & $70.45(5.94)$ & $72.43(6.98)$ & 1.617 & 0.200 \\
\hline $\operatorname{Sex}(\%)$ & & & & 10.692 & 0.005 \\
\hline Male & $109(47.8)$ & $20(36.4)$ & $20(27.0)$ & & \\
\hline Female & $119(52.2)$ & $35(63.6)$ & $54(73.0)$ & & \\
\hline Education, N (\%) & & & & 9.568 & 0.144 \\
\hline$\leq 6$ & $97(42.5)$ & $23(41.8)$ & $35(47.3)$ & & \\
\hline 7 to 11 & $35(15.4)$ & $16(29.1)$ & $10(13.5)$ & & \\
\hline 12 & $43(18.9)$ & $8(14.5)$ & $17(23.0)$ & & \\
\hline$>12$ & $53(23.2)$ & $8(14.5)$ & $12(16.2)$ & & \\
\hline \multicolumn{2}{|c|}{ Income (thousand KRW per month), N (\%) } & & & 6.133 & 0.632 \\
\hline Over 5,000 & $19(9.3)$ & $3(5.7)$ & $5(6.9)$ & & \\
\hline 3,000 to 5,000 & $34(16.6)$ & $8(15.1)$ & $13(18.1)$ & & \\
\hline 2,000 to 1,000 & $43(21.0)$ & $13(24.5)$ & $13(18.1)$ & & \\
\hline Under 1,000 & $37(18.0)$ & $16(30.2)$ & $16(22.2)$ & & \\
\hline None & $72(35.1)$ & $13(24.5)$ & $25(34.7)$ & & \\
\hline Employment, N (\%) & & & & 10.781 & 0.005 \\
\hline Not employed & $153(73.9)$ & $44(83.0)$ & $66(91.7)$ & & \\
\hline Employed & $54(26.1)$ & $9(17.0)$ & $6(8.3)$ & & \\
\hline Marriage status, N (\%) & & & & 7.087 & 0.131 \\
\hline Married & $140(67.0)$ & $36(67.9)$ & $52(72.2)$ & & \\
\hline Bereavement & $58(27.8)$ & $17(32.1)$ & $20(27.8)$ & & \\
\hline Divorced & $11(5.3)$ & $0(0.0)$ & $0(0.0)$ & & \\
\hline
\end{tabular}

None group: elderly people who never experienced grandchild care, Current group: elderly people who were currently caring their grandchildren, Past group: elderly people who had cared for their grandchildren previously. N: number, SD: standard deviation 
nificantly different among the None, the Current, and the Past groups. Elderly females experienced significantly more grandchild care than elderly males, and grandparents who cared for grandchildren were less likely to work.

\section{Characteristics related to grandchild care}

Characteristics related to grandchild care are shown in Ta- ble 2. Among participants who had experienced grandchild care, $48.7 \%$ received regular financial support from their grownup children in return for the care, amounting to approximately 490,000 KRW (approximately 450 USD) per month in average. Results showed that $52.6 \%$ of grandparents started caring for their grandchildren on their own will, and $73.8 \%$ of grandparents cared for their grandchildren full-time on weekdays. Em-

Table 2. Characteristics related to grandchild care

\begin{tabular}{|c|c|c|c|c|c|}
\hline Grandchild care & Total & Current group & Past group & Statistics & $\mathrm{p}$ \\
\hline Financial support from grown-up children, N (\%) & & & & 3.336 & 0.068 \\
\hline No & $60(51.3)$ & $30(61.2)$ & $30(44.1)$ & & \\
\hline Yes & $57(48.7)$ & $19(38.8)$ & $38(55.9)$ & & \\
\hline Amount of financial support, mean (SD) & $490.2(322.0)$ & $531.3(394.1)$ & $464.0(271.8)$ & 0.420 & 0.521 \\
\hline $1,000 \mathrm{KRW}$ per month & & & & & \\
\hline Duration of grandchild care, mean (SD), month & $81.37(81.87)$ & $92.02(75.05)$ & $73.53(86.22)$ & 1.564 & 0.213 \\
\hline Motivation for grandchild care (\%) & & & & 0.601 & 0.740 \\
\hline Grandparent's own will & $60(52.6)$ & $25(52.1)$ & $35(53.0)$ & & \\
\hline By the child's request & $32(28.1)$ & $15(31.3)$ & $17(25.8)$ & & \\
\hline Grandparent's will and child's request & $22(19.3)$ & $8(16.7)$ & $14(21.2)$ & & \\
\hline Intensity of grandchild care, $\mathrm{N}(\%)$ & & & & 3.924 & 0.416 \\
\hline Daytime during weekday & $25(19.8)$ & $10(18.5)$ & $15(20.8)$ & & \\
\hline Full time during weekday & $20(15.9)$ & $9(16.7)$ & $11(15.3)$ & & \\
\hline Weekend only & $3(2.4)$ & $2(3.7)$ & $1(1.4)$ & & \\
\hline Always & $73(57.9)$ & $29(53.7)$ & $44(61.1)$ & & \\
\hline Etc & $5(4.0)$ & $4(7.4)$ & $1(1.4)$ & & \\
\hline Reason for grandchild care, $\mathrm{N}(\%)$ & & & & 19.022 & 0.002 \\
\hline Employment of both parents & $82(84.5)$ & $29(67.4)$ & $53(98.1)$ & & \\
\hline Financial difficulties & $2(2.1)$ & $2(4.7)$ & $0(0.0)$ & & \\
\hline Accidents or disease & $2(2.1)$ & $1(2.3)$ & $1(1.9)$ & & \\
\hline Death of children's parents & $5(5.2)$ & $5(11.6)$ & $0(0.0)$ & & \\
\hline Divorce of children's parents & $4(4.1)$ & $4(9.3)$ & $0(0.0)$ & & \\
\hline Missing of children's parents & $2(2.1)$ & $2(4.7)$ & $0(0.0)$ & & \\
\hline Will to continue grandchild care, $\mathrm{N}(\%)$ & & & & 1.404 & 0.496 \\
\hline Will continue caring & $27(24.8)$ & $13(26.0)$ & $14(23.7)$ & & \\
\hline According to the situation & $43(39.4)$ & $22(44.0)$ & $21(35.6)$ & & \\
\hline Don't want caring grandchildren again & $39(35.8)$ & $15(30.0)$ & $24(40.7)$ & & \\
\hline Kind of support needed, N (\%) & & & & 6.816 & 0.078 \\
\hline Financial supports & $11(23.9)$ & $8(38.1)$ & $3(12.0)$ & & \\
\hline Academic supports for grandchildren & $3(6.5)$ & $2(9.5)$ & $1(4.0)$ & & \\
\hline Caring support for grandchildren & $29(63.0)$ & $9(42.9)$ & $20(80.0)$ & & \\
\hline Assistance for housework & $3(6.5)$ & $2(9.5)$ & $1(4.0)$ & & \\
\hline Benefits from the grandchild care, $\mathrm{N}(\%)$ & & & & 0.684 & 0.408 \\
\hline No & $21(23.2)$ & $7(18.9)$ & $14(26.4)$ & & \\
\hline Yes & $69(76.7)$ & $30(81.1)$ & $39(73.6)$ & & \\
\hline
\end{tabular}

Current group: elderly people who were currently caring for their grandchildren, Past group: elderly people who had cared for their grandchildren previously. N: number, SD: standard deviation 
ployment of both parents of the grandchildren was the biggest reason for grandchild care (84.5\%). When asked whether they were willing to continue grandchild care, $35.8 \%$ responded "No".

\section{Perceived health status and social support}

The perceived health statuses and social support of the None, the Current, and the Past groups are shown in Table 3. None of the groups' subscales of perceived health status and social support differed significantly.

The perceived health statuses and social support of the Pay group and the No pay group are shown in Table 4. Scores on some subscales of the SF-36, including role limitation by physical problem, role limitation by emotional problem, social function, bodily pain, total mental health, and total physical health, were significantly lower in the No pay group than in the Pay group in model 1. In model 2, role limitation by physical problem, role limitation by emotional problem subscales, and social function on the SF-36 were significantly different between the two groups. None of the subscales on the SF-36 were significantly different between the groups in model 3 . Although not shown in Table 4, there was no main effect of intensity of grandchild care on any of the subscales on the SF- 36 when included as a covariate in model 3.

Also, none of the subscales on the MOS-SSS were significantly different between the two groups in all models.

\section{Associations between regular financial support and scores on the SF-36 and the MOS-SSS subscales}

GLM analysis with the covariates of age, sex, education level, household income level, marital status, employment status, and regular financial support from grown-up children in model 1 found that regular financial support was positively associated with scores on the physical role, emotional role, and total mental health subscales of the SF-36 (Table 5). However, this association disappeared when intensity of grandchild care was included as a covariate in model 2 (Table 5, Supplementary Table 1 in the online-only Data Supplement). The amount of financial support received was not significantly correlated with the scores on any of the subscales on the SF-36 or the MOS-SSS (Supplementary Table 2 in the online-only Data Supplement).

\section{DISCUSSION}

Our study investigated the factors related to grandchild care and the perceived health status of grandparents. Among all participants, about $36.1 \%$ of elderly individuals were found to have experienced grandchild care. This is comparable with the previous study that reported the prevalence of $37.2 \%$ in South Korea. ${ }^{5}$ However, there was one study where the prevalence of grandchild care by grandparents had been compared between

Table 3. Differences of perceived health and social support between the groups

\begin{tabular}{|c|c|c|c|c|c|}
\hline Group & None group $(\mathrm{N}=219)$ & Current group $(\mathrm{N}=54)$ & Past group $(\mathrm{N}=74)$ & Statistics & $\mathrm{p}$ \\
\hline \multicolumn{6}{|l|}{ SF-36, mean (SD) } \\
\hline General health & $39.61(22.1)$ & $41.11(16.95)$ & $41.42(18.05)$ & 0.272 & 0.762 \\
\hline Physical function & $62.97(32.15)$ & $66.85(27.1)$ & $61.01(28.91)$ & 0.574 & 0.564 \\
\hline Role limitation, physical & $74.23(29.47)$ & $79.28(25.26)$ & $75.08(27.11)$ & 0.688 & 0.503 \\
\hline Role limitation, emotional & $84.28(24.43)$ & $84.41(20.8)$ & $85.36(23.28)$ & 0.058 & 0.944 \\
\hline Social function & $80.88(25.57)$ & $84.26(21.88)$ & $82.94(23.28)$ & 0.504 & 0.605 \\
\hline Bodily pain & $61.74(23.88)$ & $62.96(23.68)$ & $63.38(23.48)$ & 0.159 & 0.853 \\
\hline Vitality & $51.23(17.93)$ & $50(16.51)$ & $51.69(15.67)$ & 0.158 & 0.854 \\
\hline Mental health & $63.58(19.22)$ & $62.87(17.82)$ & $68.45(16.76)$ & 2.159 & 0.117 \\
\hline Total mental health & $66.94(17.49)$ & $66.88(14.98)$ & $69.35(15.62)$ & 0.610 & 0.544 \\
\hline Total physical health & $58.4(24.37)$ & $61.48(20.24)$ & $58.85(20.98)$ & 0.387 & 0.680 \\
\hline SF-36 total score & $62.28(20.18)$ & $63.86(16.29)$ & $63.67(17.05)$ & 0.241 & 0.786 \\
\hline \multicolumn{6}{|l|}{ MOS-SSS, mean (SD) } \\
\hline Emotional/informational & $59.61(23.54)$ & $64.64(27.11)$ & $62.2(27.57)$ & 0.992 & 0.372 \\
\hline Tangible & $69.32(24.03)$ & $71.93(27.83)$ & $72(25.56)$ & 0.450 & 0.638 \\
\hline Positive & $60.14(26.1)$ & $66.44(28.82)$ & $67.27(28.1)$ & 2.532 & 0.081 \\
\hline Affectionate & $62.42(25.89)$ & $65.43(30.52)$ & $65.75(28.95)$ & 0.551 & 0.577 \\
\hline Overall & $62.17(21.94)$ & $66.56(25.4)$ & $65.83(24.52)$ & 1.186 & 0.307 \\
\hline
\end{tabular}

None group: elderly people who never experienced grandchild care, Current group: elderly people who were currently caring for their grandchildren, Past group: elderly people who had previously cared for their grandchildren. SF-36: the Medical Outcome Survey (MOS) 36-item short-form health survey, MOS-SSS: the Medical Outcome Survey Social Support Survey, N: number, SD: standard deviation 
two countries, Chinese (57.6\%) and Korea (5.6\%) and the number was much lower than in this study. ${ }^{24}$ The worldwide provision of grandchild care is reportedly increasing despite the wide range in cultures and social systems (i.e., about 50\% in Europe and $24 \%$ in the United States). ${ }^{1,3}$

Although $71.9 \%$ of grandparents had started caring for their grandchild part-time or full-time on their own will, about $35.8 \%$ of grandparents reported they did not want to continue caring for their grandchildren in the future. This finding implicates that caring for grandchild might be burden for grandparents to keep up with. This burden might be caused by the long periods of time required for grandchild care. Most of the

Table 4. Differences of perceived health and social support between the groups who received financial support from their adult child in return for grandchild care or not

\begin{tabular}{|c|c|c|c|c|c|c|c|c|}
\hline \multirow{2}{*}{ Group } & \multirow{2}{*}{$\begin{array}{l}\text { No pay group } \\
(\mathrm{N}=60)\end{array}$} & \multirow{2}{*}{$\begin{array}{l}\text { Pay group } \\
(\mathrm{N}=57)\end{array}$} & \multicolumn{2}{|c|}{ Model 1} & \multicolumn{2}{|c|}{ Model 2} & \multicolumn{2}{|c|}{ Model 3} \\
\hline & & & $\mathrm{F}$ & $\mathrm{p}$ & $\mathrm{F}$ & $\mathrm{p}$ & $\mathrm{F}$ & $\mathrm{p}$ \\
\hline \multicolumn{9}{|l|}{ SF-36, mean (SD) } \\
\hline General health & $39.83(17.39)$ & $42.72(18.40)$ & 0.873 & 0.352 & 0.103 & 0.749 & 0.042 & 0.837 \\
\hline Physical function & $59.5(30.18)$ & $67.89(27.16)$ & 2.328 & 0.130 & 0.403 & 0.527 & 0.021 & 0.884 \\
\hline Role limatation, physical & $69.48(32.04)$ & $83.99(18.94)$ & 8.315 & $0.005^{*}$ & 4.926 & $0.029^{*}$ & 2.035 & 0.157 \\
\hline Role limitation, emotional & $78.47(27.24)$ & $91.08(14.42)$ & 9.247 & $0.003^{*}$ & 5.895 & $0.017^{*}$ & 3.089 & 0.082 \\
\hline Social function & $78.54(28.10)$ & $87.5(15.13)$ & 5.636 & $0.019^{*}$ & 3.932 & $0.050^{*}$ & 1.544 & 0.217 \\
\hline Bodily pain & $58.67(26.52)$ & $68.07(19.95)$ & 4.237 & $0.042^{*}$ & 1.644 & 0.203 & 0.289 & 0.592 \\
\hline Vitality & $47.92(16.94)$ & $52.63(14.98)$ & 2.422 & 0.122 & 1.295 & 0.258 & 0.372 & 0.543 \\
\hline Mental health & $64.00(17.68)$ & $67.54(17.76)$ & 1.179 & 0.280 & 1.329 & 0.252 & 0.322 & 0.572 \\
\hline Total mental health & $64.58(17.27)$ & $71.27(12.83)$ & 5.536 & $0.020^{*}$ & 3.881 & 0.052 & 1.472 & 0.228 \\
\hline Total physical health & $55.83(23.14)$ & $64.19(18.29)$ & 4.454 & $0.037^{*}$ & 1.630 & 0.205 & 0.195 & 0.660 \\
\hline SF-36 total score & $59.85(18.73)$ & $67.37(14.23)$ & 5.873 & $0.017^{*}$ & 2.919 & 0.091 & 0.699 & 0.405 \\
\hline \multicolumn{9}{|l|}{ MOS-SSS; mean (SD) } \\
\hline Emotional/informational & $63.18(30.06)$ & $61.61(25.36)$ & 0.093 & 0.761 & 0.038 & 0.845 & 0.259 & 0.612 \\
\hline Tangible & $72.40(28.61)$ & $70.45(25.44)$ & 0.109 & 0.742 & 0.001 & 0.974 & 0.247 & 0.620 \\
\hline Positive & $67.37(28.05)$ & $64.06(29.85)$ & 0.415 & 0.521 & 0.436 & 0.510 & 0.025 & 0.874 \\
\hline Affectionate & $64.17(30.74)$ & $65.18(30.07)$ & 0.010 & 0.919 & 0.020 & 0.886 & 0.026 & 0.872 \\
\hline Overall & $66.08(26.32)$ & $64.40(24.57)$ & 0.123 & 0.726 & 0.002 & 0.963 & 0.115 & 0.735 \\
\hline
\end{tabular}

${ }^{*} \mathrm{p}<0.05$. Model 1: crude model without any covariates, Model 2: includes the age, sex, educational level, household income level, and marital and employment status as covariates, Model 3: includes the intensity of caring for grandchildren as a covariate in addition to model 2. No pay group: grandparents who received regular financial support in return for grandchild care, Pay group: grandparents who did not receive regular financial support in return for grandchild care. SF-36: Medical Outcome Survey (MOS) 36-item short-form health survey, MOS-SSS: Medical Outcome Survey Social Support Survey, N: number, SD: standard deviation

Table 5. Generalized linear model for scores on subscales of the SF-36 according to financial support (N=116)

\begin{tabular}{|c|c|c|c|c|c|c|}
\hline & \multicolumn{3}{|c|}{ Model 1} & \multicolumn{3}{|c|}{ Model 2} \\
\hline & B & $95 \% \mathrm{CI}$ & $\mathrm{p}$ & B & $95 \% \mathrm{CI}$ & $\mathrm{p}$ \\
\hline \multicolumn{7}{|c|}{ No Financial support from grown-up children referent } \\
\hline \multicolumn{7}{|l|}{ Financial support } \\
\hline Role limitation by physical & 11.0 & 1.9 to 20.1 & $0.017^{*}$ & 7.38 & -1.9 to 16.7 & 0.119 \\
\hline Role limitation by emotional & 10.7 & 2.7 to 18.8 & $0.009^{*}$ & 7.8 & -0.2 to 15.7 & 0.054 \\
\hline Social function & 8.2 & -0.1 to 16.5 & 0.053 & 5.1 & -3.3 to 13.5 & 0.233 \\
\hline Bodily pain & 5.7 & -2.3 to 13.7 & 0.161 & 2.6 & -5.7 to 10.8 & 0.540 \\
\hline Total mental health & 6.1 & 0.4 to 11.8 & $0.036^{*}$ & 3.8 & -1.9 to 9.5 & 0.188 \\
\hline Total physical health & 4.7 & -2.1 to 11.6 & 0.177 & 1.7 & -5.3 to 8.6 & 0.639 \\
\hline SF-36 total score & 5.4 & -0.4 to 11.2 & 0.070 & 2.7 & -3.1 to 8.5 & 0.365 \\
\hline
\end{tabular}

${ }^{*} \mathrm{p}<0.05$. Model 1: includes the age, sex, educational level, household income level, and marital and employment status as covariates, Model 2: includes the intensity of caring for grandchildren as a covariate in addition to model 1 
grandparents (93.7\%) spent their time regularly on grandchild caring, longer than daytime on weekdays. Furthermore, 59.7\% of the grandparents always cared for their grandchild. These are large burdens compared to the results reported in Western countries. For example, a European study reported that only $32.4 \%$ of grandparents caring for a grandchild provided intensive care, which had been defined as "looking after at least one grandchild almost daily or for at least 15 hours a week." In this study, grandparents also responded that "caring support for grandchildren" was the most needed form of by their own grown-up children (63.0\%). However, despite the burden of parenting, grandparents also did report benefits from caring for their grandchildren (76.7\%). This is consistent with the findings of previous studies, which reported positive associations between grandchild care and the wellbeing of grandparents. ${ }^{7,8,10}$

The fact that there were no significant differences in scores on any of the SF-36 subscales in the None, the Past, and the Current groups suggests that taking care of grandchildren itself did not have significant effect on the perceived health status of grandparents and that there might be other relevant factors. The fact that there were no significant differences in the scores for any of the MOS-SSS subscales in three groups also suggests that raising grandchildren itself did not have direct impact on perceived social support.

Interestingly, role limitation by physical, role limitation by emotional, social function, and bodily pain subscales of the SF-36 were significantly different in the Pay and the No pay groups. This means that regular financial support in return for grandchild care is a mediating factor related to the perceived health status by grandparents.

Despite few studies, financial support from grown-up children in return for grandchild care has been beneficial to the psychological well-being of grandparents, which is consistent with our findings. ${ }^{23,28}$ For instance, Cong and Silverstein ${ }^{23}$ reported that financial support from grown-up children reduced depression of grandparents. This could be explained by the financial benefits themselves or by acknowledgement for their role. Although we did not explore the direct reason for the beneficial effect of financial support, $23.9 \%$ of the grandparents claimed "financial support" to be the most needed form of support for grandchild care, which indicates a perceived financial burden associated with grandchild care. This suggests that financial support effectively mitigates the financial burden.

However, when asked the reason for grandchild care, $84.5 \%$ claimed the employment of both parents, and only $2.1 \%$ claimed financial difficulties. In particular, the amount of transferred money was not significantly correlated with the SF- 36 subscale scores. This suggests that financial support from grown-up children could have been meant other than the mitigation of financial burden. Cong and Silverstein ${ }^{23}$ reported that financial support promoted psychological benefits when accompanied by full-time grandchild care and argued that intergenerational "time-for-money" reciprocity would be not only a survival strategy to ensure economic prosperity but also contributes positively to the psychological wellbeing of grandparents.

During grandchild care, grandparents might encounter a dilemma between altruism (the pleasure of caring for grandchildren) and exploitation (the sense of being unrecognized and under-valued). ${ }^{29}$ When a tangible reward is lacking, the grandparents might feel unfairly treated by their grown-up children. ${ }^{30}$ Meanwhile, financial remittance in return for grandchild care would signify an acknowledgement for their contribution by their own children and serve as psychological reward for grandparents. This acknowledgement may help to preserve grandparents' self-esteem and self-efficacy. ${ }^{23}$

Grandchild care is structurally ambivalent. Although it can be a joyful task to spend time with beloved grandchildren, it can also be perceived as a stressful burden that constrains an individual's freedom. The feeling that the support from their own children has been "earned" may help mitigate the psychological distress caused by burden of long periods of care and limitation to the grandparents' freedom. In our study, these are thought to be the reasons that regular financial support in return for grandchild care was positively associated with perceived health status, especially in the sense of role limitation by both physical and emotional problem.

Another interesting finding of our study was that the significance of the association between financial support and subscale scores on the SF-36 disappeared when the intensity of grandchild care was included as a covariate, although the intensity of grandchild care had no independent effect on the scores. This finding suggests that the intensity of grandchild care may be another strong mediating factor for the perceived health status of elderly people caring for a grandchild. This result is consistent with previous studies reporting that the intensity of grandchild care was the critical factor for mental health of grandparents caring for grandchildren. ${ }^{16,17}$

Our study has some limitations. First, the sample size was small, which limits the generalization of the findings in our study. A study with a larger sample size is needed to confirm our findings. Second, we did not include a qualitative in-depth interview, which limited our investigation of the delicate and complicated feelings that grandparents may have regarding grandchild care and financial remittance. Whether the financial support from their own children had been included in the grandparents' reported monthly household income or had covered the costs of caring for grandchildren was not known; these factors may also affect grandparents' satisfaction when they take care of their grandchildren. Future study with an 
in-depth interview would help clarify grandparents' feelings and may indicate more useful clinical implication to enhance the health of grandparents.

In conclusion, despite some limitations, our findings indicate that regular financial support to grandparents in return for grandchild care may be positively associated with the perceived health status of grandparents. These findings have important social implications and warrant future study to reveal the psychological mechanism of these associations and enhance the health of elderly individuals.

\section{Supplementary Materials}

The online-only Data Supplement is available with this article at https://doi.org/10.30773/pi.2019.0115.

\section{Acknowledgments}

The Mental Health Care Program was financially supported by the Suseong District Office, Daegu, Korea. The funding source had no involvement in any of study design and collection, analysis and interpretation of data, and writing of the article.

\section{Conflicts of Interest}

The authors have no potential conflicts of interest to disclose.

\section{Author Contributions}

Conceptualization: Jung Jae Lee. Data curation: Jung Jae Lee, Un Sun Chung. Formal analysis: Jung Jae Lee, Kyung Min Kim. Funding acquisition: Jung Jae Lee, Un Sun Chung. Investigation: Jung Jae Lee, Kyung Min Kim. Methodology: Jung Jae Lee, Un Sun Chung. Project administration: Jung Jae Lee. Resources: Jung Jae Lee, Un Sun Chung. Visualization: Kyung Min Kim, Un Sun Chung. Writing_original draft: Kyung Min Kim, Jung Jae Lee. Writing_-review \& editing: Un Sun Chung, Kyung Min Kim.

\section{ORCID iDs}

$\begin{array}{ll}\text { Kyung Min Kim } & \text { https://orcid.org/0000-0003-0577-0701 } \\ \text { Jung Jae Lee } & \text { https://orcid.org/0000-0002-0828-3557 } \\ \text { Un Sun Chung } & \text { https://orcid.org/0000-0003-3871-1425 }\end{array}$

\section{REFERENCES}

1. Hank K, Buber I. Grandparents caring for their grandchildren: findings from the 2004 survey of health, ageing, and retirement in Europe. J Fam Issues 2009;30:53-73.

2. U.S. Bureau of the Census Table CH-7. Grandchildren living in the home of their grandparents: 1970-present. 2014. Available at: http:// www.census.gov/population/socdemo/hh-fam/tabCH-7.pdf. Accessed October 25, 2018.

3. Laughlin L. Who's minding the kids? Child care arrangements: Spring 2011. US Census Bureau. 2013. Available at: https://www.census.gov/ prod/2013pubs/p70-135.pdf. Accessed October 25, 2018

4. Tsai FJ, Motamed S, Rougemont A. The protective effect of taking care of grandchildren on elders' mental health? Associations between changing patterns of intergenerational exchanges and the reduction of elders' loneliness and depression between 1993 and 2007 in Taiwan. BMC Public Health 2013;13:567.

5. Ministry of Health and Welfare. 2015 National Childcare Survey. 2016. Available at: http://www.prism.go.kr/homepage/researchCommon/ downloadResearchAttachFile.do;jsessionid=3C9C5A4FDEE346DFC2 749F455D85E03A.node02?work_key $=001 \&$ file_type $=$ CPR\&seq no $=002 \&$ pdf_conv_yn $=Y \&$ research_id $=1351000-201600003$. Accessed October 20, 2018.
6. Di Gessa G, Glaser K, Tinker A. The impact of caring for grandchildren on the health of grandparents in Europe: A lifecourse approach. Soc Sci Med 2016;152:166-175.

7. Di Gessa G, Glaser K, Tinker A. The health impact of intensive and nonintensive grandchild care in Europe: New evidence from SHARE. J Gerontol B Psychol Sci Soc Sci 2015;71:867-879.

8. Ku LJ, Stearns SC, Van Houtven CH, Lee SY, Dilworth-Anderson P, Konrad TR. Impact of caring for grandchildren on the health of grandparents in Taiwan. J Gerontol B Psychol Sci Soc Sci 2013;68:1009-1021.

9. Grundy EM, Albala C, Allen E, Dangour AD, Elbourne D, Uauy R. Grandparenting and psychosocial health among older Chileans: A longitudinal analysis. Aging Ment Health 2012;16:1047-1057.

10. Hierholzer R. Improvement in PTSD patients who care for their grandchildren. Am J Psychiatry 2004;161:176-177.

11. Minkler M, Fuller-Thomson E. The health of grandparents raising grandchildren: results of a national study. Am J Public Health 1999;89: 1384-1389.

12. Blustein J, Chan S, Guanais FC. Elevated depressive symptoms among caregiving grandparents. Health Services Res 2004;39:1671-1690.

13. Hayslip B, Fruhauf CA, Dolbin-MacNab ML. Grandparents raising grandchildren: What have we learned over the past decade? Gerontologist 2017;57;1196.

14. Dunne EG, Kettler LJ. Grandparents raising grandchildren in Australia: Exploring psychological health and grandparents' experience of providing kinship care. Int J Soc Welfare 2008;17:333-345.

15. Arpino B, Bordone V. Does grandparenting pay off? The effect of child care on grandparents' cognitive functioning. J Marriage Fam 2014;76: 337-351.

16. Coall DA, Hertwig R. Grandparental investment: Past, present, and future. Behav Brain Sci 2010;33:1-19.

17. Chen F, Liu G. The health implications of grandparents caring for grandchildren in China. J Gerontol B Psychol Sci Soc Sci 2011;67:99-112.

18. Hughes ME, Waite LJ, LaPierre TA, Luo Y. All in the family: The impact of caring for grandchildren on grandparents' health. J Gerontol B Psychol Sci Soc Sci 2007;62:S108-S119.

19. Hayslip Jr B, Blumenthal H, Garner A. Social support and grandparent caregiver health: One-year longitudinal findings for grandparents raising their grandchildren. J Gerontol B Psychol Sci Soc Sci 2014;70:804812 .

20. Musil C, Warner C, Zauszniewski J, Wykle M, Standing T. Grandmother caregiving, family stress and strain, and depressive symptoms. West J Nurs Res 2009;31:389-408.

21. Doley R, Bell R, Watt B, Simpson H. Grandparents raising grandchildren: Investigating factors associated with distress among custodial grandparent. J Fam Stud 2015;21:101-119.

22. Collins WL. A strengths-based support group to empower African American grandmothers raising grandchildren. Soc Work Christian 2011;38:453.

23. Cong Z, Silverstein M. Intergenerational time-for-money exchanges in rural China: does reciprocity reduce depressive symptoms of older grandparents? Res Human Devel 2008;5:6-25.

24. Ko PC, Hank K. Grandparents caring for grandchildren in China and Korea: findings from CHARLS and KLoSA. J Gerontol B Psychol Sci Soc Sci 2013;69:646-651.

25. Arthur S, Snape D, Dench G. The moral economy of grandparenting. Generations Rev 2003;13:10-12.

26. Ware Jr JE, Sherbourne CD. The MOS 36-item short-form health survey (SF-36): I. Conceptual framework and item selection. Med Care 1992;30:473-483.

27. Sherbourne CD, Stewart AL. The MOS social support survey. Soc Sci Med 1991;32:705-714.

28. Silverstein M, Cong Z, Li S. Intergenerational transfers and living arrangements of older people in rural China: Consequences for psychological well-being. J Gerontol B Psychol Sci Soc Sci 2006;61:S256-S266.

29. Goodfellow J, Laverty J. Grandparents supporting working families. Fam Matters 2003;66:14-19.

30. Goh EC. Grandparents as childcare providers: an in-depth analysis of the case of Xiamen, China. J Aging Stud 2009;23:60-68. 
Supplementary Table 1. Generalized linear model for scores on subscales of the SF-36

\begin{tabular}{|c|c|c|c|c|c|c|c|c|c|c|c|c|c|c|c|c|c|c|c|c|c|c|c|c|}
\hline & \multicolumn{4}{|c|}{ Role limitation, physical } & \multicolumn{4}{|c|}{ Role limitation, emotional } & \multicolumn{4}{|c|}{ Social function } & \multicolumn{4}{|c|}{ Bodily pain } & \multicolumn{4}{|c|}{$\begin{array}{l}\text { Total mental health } \\
\end{array}$} & \multicolumn{4}{|c|}{ Total physical health } \\
\hline & \multirow{2}{*}{ B } & \multicolumn{2}{|c|}{$95 \% \mathrm{CI}$} & \multirow{2}{*}{$\mathrm{p}$} & \multirow{2}{*}{ B } & \multicolumn{2}{|c|}{$95 \%$ CI } & \multirow{2}{*}{$\mathrm{p}$} & \multirow{2}{*}{ B } & \multicolumn{2}{|c|}{$95 \% \mathrm{CI}$} & \multirow{2}{*}{$\mathrm{p}$} & \multirow{2}{*}{ B } & \multicolumn{2}{|c|}{$95 \% \mathrm{CI}$} & & \multirow{2}{*}{ B } & \multicolumn{2}{|c|}{$95 \%$ CI } & & $B$ & & & \\
\hline & & lower & upper & & & lower & upper & & & lower & upper & & & lower & upper & & & lower & upper & 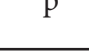 & & lower & upper & ${ }_{p}$ \\
\hline Age & -1.27 & -2.03 & -0.51 & 0.001 & -0.457 & -1.10 & 0.19 & 0.166 & -0.371 & -1.05 & 0.31 & 0.286 & -1.291 & -1.96 & -0.62 & 0.000 & -0.205 & -0.67 & 0.26 & 0.387 & -1.229 & -1.80 & -0.66 & 0.000 \\
\hline Sex & & & & & & & & & & & & & & & & & & & & & & & & \\
\hline Male & Referent & & & & Referent & & & & Referent & & & & Referent & & & & Referent & & & & Referent & & & \\
\hline Female & -9.66 & -22.26 & 2.95 & 0.133 & -6.089 & -16.88 & 4.70 & 0.269 & -5.810 & -17.17 & 5.55 & 0.316 & -12.430 & -23.64 & -1.23 & .0300 & -6.682 & -14.43 & 1.07 & 0.091 & -12.640 & -22.10 & -3.19 & 0.009 \\
\hline Educational level & & & & & & & & & & & & & & & & & & & & & & & & \\
\hline$\leq 6$ & Referent & & & & Referent & & & & Referent & & & & Referent & & & & Referent & & & & Referent & & & \\
\hline 7 to 11 & 2.61 & -9.33 & 14.56 & 0.668 & -1.198 & -11.42 & 9.02 & 0.818 & 2.040 & -8.73 & 12.81 & 0.710 & 2.119 & -8.50 & 12.74 & 0.696 & -2.528 & -9.84 & 4.79 & 0.498 & 4.036 & -4.92 & 12.99 & 0.377 \\
\hline 12 & 10.48 & -1.95 & 22.91 & 0.099 & 1.633 & -9.01 & 12.27 & 0.764 & -0.265 & -11.47 & 10.95 & 0.963 & 11.195 & 0.14 & 22.25 & 0.047 & -1.152 & -8.77 & 6.46 & 0.767 & 7.872 & -1.46 & 17.20 & 0.098 \\
\hline$>12$ & 10.19 & -5.51 & 25.90 & 0.203 & -0.884 & -14.33 & 12.56 & 0.897 & -6.530 & -20.69 & 7.63 & 0.366 & 4.424 & -9.54 & 18.39 & 0.535 & -3.087 & -12.84 & 6.67 & 0.535 & 6.742 & -5.04 & 18.52 & 0.262 \\
\hline Income & & & & & & & & & & & & & & & & & & & & & & & & \\
\hline Over 5,000 & Referent & & & & Referent & & & & Referent & & & & Referent & & & & Referent & & & & Referent & & & \\
\hline 3,000 to 5,000 & -9.15 & -28.69 & 10.39 & 0.359 & -0.152 & -16.87 & 16.57 & 0.986 & -2.612 & -20.23 & 15.00 & 0.771 & 0.833 & -16.54 & 18.20 & 0.925 & -1.291 & -13.26 & 10.68 & 0.833 & -2.907 & -17.56 & 11.75 & 0.697 \\
\hline 2,000 to 1,000 & 3.53 & -16.17 & 23.23 & 0.726 & 0.379 & -16.48 & 17.24 & 0.965 & 0.179 & -17.58 & 17.94 & 0.984 & 10.933 & -6.58 & 28.45 & 0.221 & .479 & -11.71 & 12.67 & 0.939 & 3.390 & -11.39 & 18.17 & 0.653 \\
\hline Under 1,000 & 0.78 & -17.74 & 19.31 & 0.934 & -7.046 & -22.90 & 8.80 & 0.384 & 2.924 & -13.77 & 19.62 & 0.731 & 10.929 & -5.54 & 27.39 & 0.193 & -1.772 & -13.13 & 9.58 & 0.760 & 5.449 & -8.44 & 19.34 & 0.442 \\
\hline None & 0.35 & -18.27 & 18.97 & 0.971 & -11.462 & -27.40 & 4.47 & 0.159 & -6.881 & -23.67 & 9.91 & 0.422 & 11.200 & -5.35 & 27.75 & 0.185 & -7.382 & -18.81 & 4.04 & 0.205 & 1.320 & -12.65 & 15.29 & 0.853 \\
\hline Marriage & & & & & & & & & & & & & & & & & & & & & & & & \\
\hline Married & Referent & & & & Referent & & & & Referent & & & & Referent & & & & Referent & & & & Referent & & & \\
\hline Bereavement & 0.84 & -9.68 & 11.36 & 0.875 & 2.031 & -6.97 & 11.03 & 0.658 & -3.075 & -12.56 & 6.41 & 0.525 & 0.900 & -8.45 & 10.25 & 0.850 & 1.301 & -5.14 & 7.74 & 0.692 & 3.122 & -4.77 & 11.01 & 0.438 \\
\hline Employment & & & & & & & & & & & & & & & & & & & & & & & & \\
\hline Not employed & Referent & & & & Referent & & & & Referent & & & & Referent & & & & Referent & & & & Referent & & & \\
\hline Employed & 5.37 & -10.00 & 20.74 & 0.493 & 0.260 & -12.89 & 13.41 & 0.969 & 3.713 & -10.14 & 17.57 & 0.599 & -1.041 & -14.70 & 12.62 & 0.881 & -1.932 & -11.38 & 7.51 & 0.688 & -0.364 & -11.89 & 11.16 & 0.951 \\
\hline Intensity of grandchild care & & & & & & & & & & & & & & & & & & & & & & & & \\
\hline Daytime during weekday & Referent & & & & Referent & & & & Referent & & & & Referent & & & & Referent & & & & Referent & & & \\
\hline Full time during weekday & 11.25 & -3.22 & 25.71 & 0.128 & 8.409 & -3.97 & 20.79 & 0.183 & 13.082 & 0.04 & 26.12 & 0.049 & 12.196 & -0.66 & 25.05 & 0.063 & 8.627 & -0.23 & 17.49 & 0.560 & 13.785 & 2.94 & 24.64 & 0.013 \\
\hline Only weekend & -6.14 & -34.65 & 22.36 & 0.673 & 1.132 & -23.26 & 25.53 & 0.928 & 6.970 & -18.73 & 32.67 & 0.595 & -7.861 & -33.20 & 17.48 & 0.543 & -1.846 & -19.32 & 15.62 & 0.836 & 1.411 & -19.97 & 22.79 & 0.897 \\
\hline Always & 3.88 & -7.51 & 15.26 & 0.504 & 1.669 & -8.07 & 11.41 & 0.737 & 2.963 & -7.30 & 13.23 & 0.572 & 5.399 & -4.72 & 15.52 & 0.296 & 1.231 & -5.75 & 8.22 & 0.730 & 4.719 & -3.82 & 13.26 & 0.279 \\
\hline Etc & 5.10 & -17.99 & 28.19 & 0.665 & 9.881 & -9.88 & 29.64 & 0.327 & 6.302 & -14.52 & 27.12 & 0.553 & 11.303 & -9.23 & 31.83 & 0.281 & 11.342 & -2.82 & 25.51 & 0.117 & 9.417 & -7.91 & 26.74 & 0.287 \\
\hline Financial support & & & & & & & & & & & & & & & & & & & & & & & & \\
\hline No & Referent & & & & Referent & & & & Referent & & & & Referent & & & & Referent & & & & Referent & & & \\
\hline Yes & 7.38 & -1.91 & 16.66 & 0.119 & 7.797 & -0.15 & 15.74 & 0.054 & 5.095 & -3.28 & 13.47 & 0.233 & 2.582 & -5.67 & 10.84 & 0.540 & 3.821 & -1.87 & 9.51 & 0.188 & 1.665 & -5.30 & 8.63 & 0.639 \\
\hline
\end{tabular}

\begin{tabular}{ccccc} 
Yes & 7.38 & -1.91 & 16.66 & 0.119 \\
\hline SF-36: the Medical Outcome Survey (MOS) & 36-item short-form health survey
\end{tabular} 
Supplementary Table 2. Correlation between the amount of financial support and scores on the SF-36 and the MOS-SSS (N=41)

\begin{tabular}{lc}
\hline & Correlation \\
\hline SF-36, mean (SD) & \\
General health & -0.100 \\
Physical function & 0.180 \\
Role limitation, physical & 0.202 \\
Role limitation, emotional & 0.060 \\
Social function & 0.096 \\
Bodily pain & 0.177 \\
Vitality & 0.124 \\
Mental health & -0.107 \\
Total mental health & 0.015 \\
Total physical health & 0.122 \\
SF-36 total score & 0.091 \\
MOS-SSS, mean (SD) & \\
Emotional/informational & -0.046 \\
Tangible & -0.028 \\
Positive & 0.034 \\
Affectionate & 0.107 \\
Overall & 0.009 \\
\hline
\end{tabular}

SF-36: the Medical Outcome Survey (MOS) 36-item short-form health survey, MOS-SSS: the Medical Outcome Survey Social Support Survey 